\title{
Determination of demographic, epidemiological, and socio-economic determinants and their potential impact on malaria transmission in Mannar and Trincomalee districts of Sri Lanka
}

Nayana Gunathilaka ${ }^{*}$, Wimaladharma Abeyewickreme ${ }^{1}$, Menaka Hapugoda ${ }^{2}$ and Rajitha Wickremasinghe ${ }^{3}$

\begin{abstract}
Background: Malaria was an endemic problem in Mannar and Trincomalee districts of Sri Lanka until the recent past. Currently, no local case has been found since October 2012. Therefore, the present study was conducted to identify existing demographic, epidemiological and socio-cultural factors in Mannar and Trincomalee districts of Sri Lanka, since there is limited information available on the potential influence of above variables responsible for low malaria transmission.

Methods: An analytical cross-sectional survey was carried out on selected demographic, epidemiological and socio-economic variables in 32 localities under eight sentinel sites (Each sentinel with four localities) using a predefined questionnaire during June-September 2012. Household heads of 45 houses from each locality were selected randomly to participate in the present study. Data were analysed using the Paired Chi Square test and Bray-Curtis method.

Results: A total of 1440 household heads were interviewed. Both districts indicated statistically acceptable similarities $(p>0.05)$ in age structure, gender, family size and presence of animals. The knowledge on malaria was observed under "Poor" category. The protective measures against mosquito bites, spraying status of houses and occupation pattern were varied significantly in both districts $(p<0.05)$. Educational level was statistically similar $(p>0.05)$ in both districts. Majority of the families were identified as living in "Moderate" house type under low economic condition. Both populations were indicated $85 \%$ similarity according to Bray-Curtis analysis.

Conclusion: Lack of awareness in these communities about the disease may facilitate to the re-emerge of malaria. Keywords: Demographic, Epidemiological, Socio-economic, Malaria
\end{abstract}

\section{Background}

Malaria is a vector borne disease transmitted between humans by adult female mosquitoes of the genus Anopheles. The disease is endemic in tropical and subtropical regions of the world [1]. Malaria was a major public

\footnotetext{
*Correspondence: n.gunathilaka@kln.ac.lk

${ }^{1}$ Department of Parasitology, Faculty of Medicine, University of Kelaniya, Colombo, Sri Lanka

Full list of author information is available at the end of the article
}

health problem in Sri Lanka in the past. The most prevalent cause of malaria was Plasmodium vivax $(70 \%)$ while the rest of the cases were caused by Plasmodium falciparum [2]. Sri Lanka has not reported a local case of malaria since October 2012. This remarkable success was achieved rapidly and largely during a protracted civil war. As recently as 2000, Sri Lanka had over 100,000 cases of malaria each year [3].

Several factors have impacted on low malaria transmission during last two decades [4]. The favourable 
factors include increased reliance on self-protection methods, early detection and treatment of patients by mobile malaria clinics. In addition, changes in socioeconomic and living standards in the community may have a positive impact on reducing malaria cases at present.

Mannar and Trincomalee districts were previously considered as highly malarious in northern and eastern provinces of Sri Lanka, respectively. As a result of resettlement and development activities there have been many changes in living standards among communities in these areas. Therefore, the objective of the present study was to determine how existing epidemiological, demographic and socio-economic factors contributed to have zero indigenous malaria and their potential impact on malaria transmission in Mannar and Trincomalee districts of Sri Lanka.

\section{Methods}

\section{Study area}

Mannar $\left(08^{\circ} 52^{\prime} \mathrm{N}, 80^{\circ} 04^{\prime} \mathrm{E}\right)$ and Trincomalee $\left(08^{\circ} 35^{\prime} \mathrm{N}\right.$, $81^{\circ} 05^{\prime} \mathrm{E}$ ) districts are located in the northern and eastern provinces of Sri Lanka which are having an area of 1996 and $2727 \mathrm{~km}^{2}$, respectively. A total of eight sentinel sites, three in the district of Mannar (Fig. 1) and five in the district of Trincomalee (Fig. 2) were selected. Each malaria sensitive sentinel site having a radius of $20 \mathrm{~km}$ was further subdivided into four localities (within $5-20 \mathrm{~km}$ ) to ensure full coverage of the sentinel site during the surveillance. Hence, a total of 32 localities in eight sentinel sites were identified and each locality was given a name code. Selection of the localities was based on past malaria history, environmental conditions, availability of breeding sites, an established agricultural community and feasibility of field operations to collect relevant data.

\section{Study design}

This analytical cross-sectional survey was carried out from June-September 2012. Two hundred houses were identified at each locality. Of them 45 houses from each locality were selected randomly to participate in the present study.

During the surveys, about 540 and 900 household heads covering 2455 and 3859 individual household members were interviewed in Mannar and Trincomalee districts, respectively. The head of the household was defined as the person who perceived by household members to be the primary decision maker in the family and the household was defined as individuals living together and taking meals from a common cooking facility. In the absence of a household head, a responsible adult above 18 years who appointed by the family was interviewed.

\section{Data collection}

Data on demographic (age, gender, family size, presence of domestic animals), epidemiological (knowledge/ awareness on malaria, potential breeding sites around houses/proximity, use of protective measures against mosquito bite, past malaria history, insecticide spraying status of the house) and socio-economic (level of education, monthly income, house type, occupation pattern of the head of household) determinants among two study populations were obtained using a structured questionnaire that was printed in English and local languages (Sinhala and Tamil).

\section{Data analysis}

Double data entry was done using Microsoft access for validation purpose before analysis. The epidemiological, demographic and socio-economic factors which may potentially influence on malaria transmission in the districts of Mannar and Trincomalee were statistically compared by using the Paired Chi Square test. The existing factors were compared with the previously recognized risk factors of malaria transmission in accordance with the already published literature. In addition, Bray-Curtis similarity clustering method (with square root transformation) was devised to investigate similarities among two study populations.

\section{Results}

\section{Demographic characteristics}

The age group of $16-50$ years was predominant both in Mannar and Trincomalee districts. Male to female ratio of both populations were approximately equal among all age groups, without any significant differences as suggested by the Chi square test ( $p>0.05$, at $95 \%$ level of confidence). Both communities were shared statistical similarities among age and gender structures $(\mathrm{p}>0.05)$. The families with 4-6 members were identified as the predominant family type in both districts followed by 1-3 and $>7$ per family (Table 1 ). When considering the presence of animals, hens were the widely reared animal among two study populations. Overall, both districts indicated statistically acceptable similarities $(\mathrm{p}>0.05)$ in terms of age structure, gender, average family size and presence of animals (Table 1).

\section{Epidemiological characteristics}

Epidemiological determinants among two study copulations are illustrated in Table 2. The knowledge on malaria among study populations in Mannar $(52.04 \% \mathrm{n}=281)$ and Trincomalee $(64.33 \%, \mathrm{n}=579)$ was characterized under "Poor" category. The majority of households were remained with no potential breeding sites. Only $0.3 \%$ $(\mathrm{n}=7)$ and $0.1 \%(\mathrm{n}=4)$ from Mannar and Trincomalee 


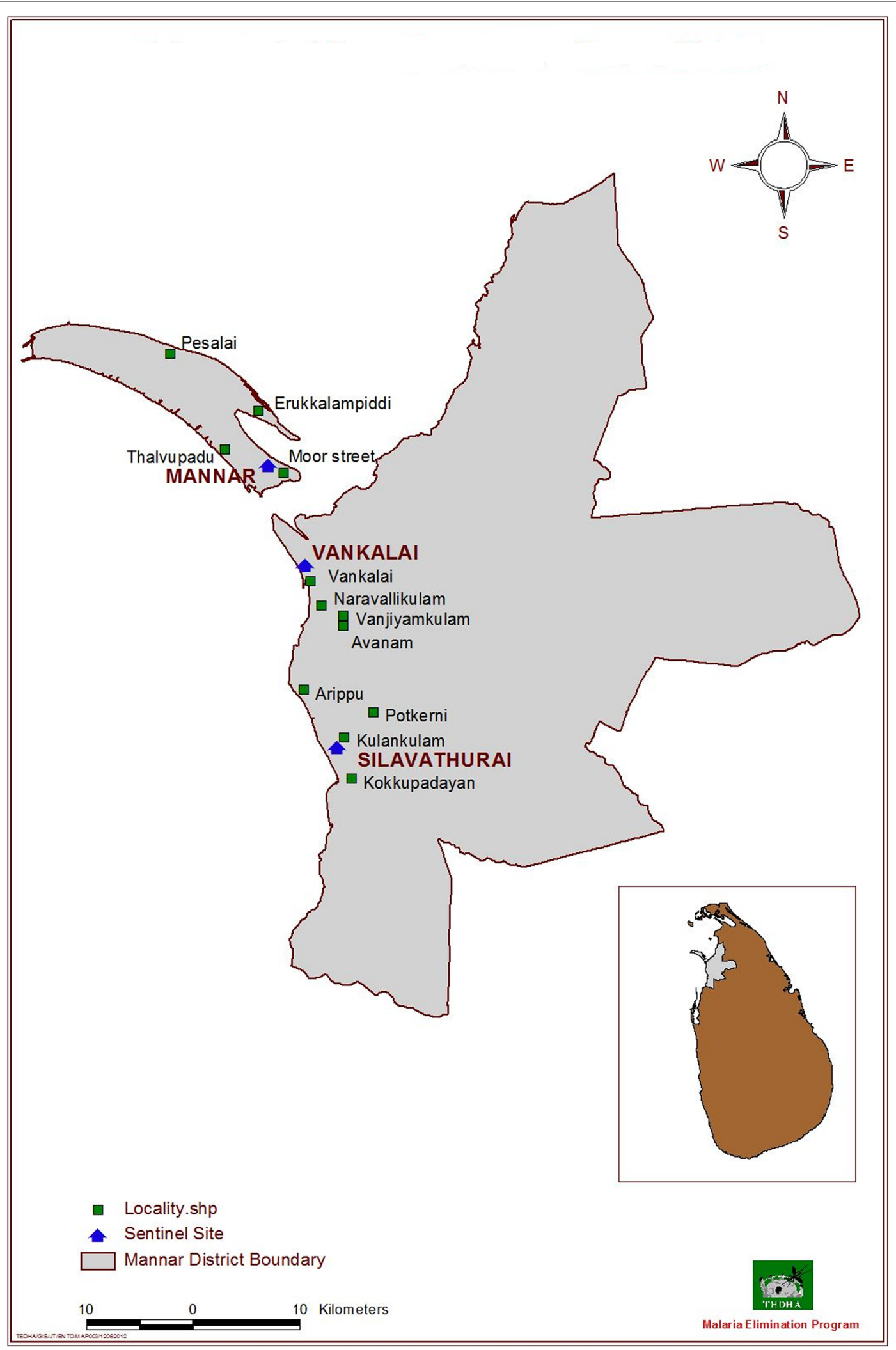

Fig. 1 Sentinel sites and localities selected for the surveys in Mannar District 


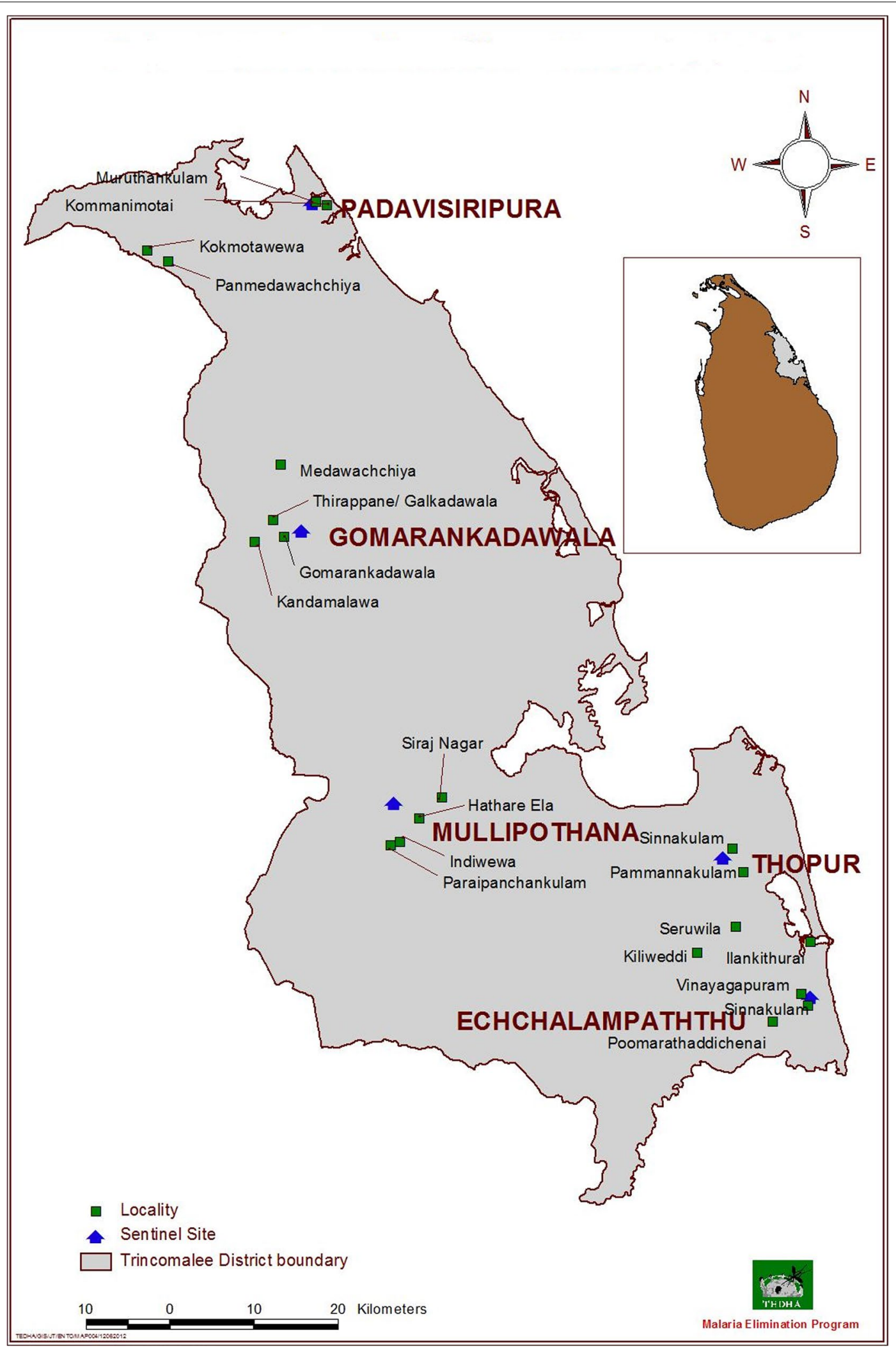

Fig. 2 Sentinel sites and localities selected for the surveys in Trincomalee District 
Table 1 Demographic characteristics and their association with malaria transmission among the study population in Mannar and Trincomalee Districts

\begin{tabular}{|c|c|c|c|c|c|c|}
\hline \multirow[t]{2}{*}{ Characteristics } & \multicolumn{2}{|c|}{ Mannar } & \multicolumn{2}{|c|}{ Trincomalee } & \multirow[t]{2}{*}{$P$} & \multirow[t]{2}{*}{$x^{2}$} \\
\hline & $\mathrm{N}$ & $\%$ & $\mathrm{~N}$ & $\%$ & & \\
\hline Age & & & & & 0.96 & 0.58 \\
\hline$<1$ & 31 & 1.26 & 79 & 2.05 & & \\
\hline $1-5$ & 239 & 9.74 & 416 & 10.78 & & \\
\hline $6-15$ & 594 & 24.20 & 884 & 22.91 & & \\
\hline $16-50$ & 1285 & 52.34 & 2095 & 54.29 & & \\
\hline$>50$ & 306 & 12.46 & 385 & 9.98 & & \\
\hline Gender & & & & & 0.83 & 0.04 \\
\hline Male & 1260 & 51.53 & 1932 & 50.06 & & \\
\hline Female & 1185 & 48.47 & 1927 & 49.94 & & \\
\hline Family size & & & & & 0.43 & 1.67 \\
\hline $1-3$ & 131 & 24.26 & 291 & 32.33 & & \\
\hline $4-6$ & 353 & 65.37 & 536 & 59.56 & & \\
\hline$>7$ & 56 & 10.37 & 74 & 8.22 & & \\
\hline Presence of animals & & & & & 0.14 & 8.18 \\
\hline Cattle & 290 & 8.16 & 866 & 17.22 & & \\
\hline Goat & 91 & 2.56 & 168 & 3.34 & & \\
\hline Dog & 195 & 5.48 & 531 & 10.56 & & \\
\hline Cat & 132 & 3.71 & 337 & 6.70 & & \\
\hline Hen & 2820 & 79.30 & 3076 & 61.15 & & \\
\hline Other & 28 & 0.79 & 52 & 1.03 & & \\
\hline
\end{tabular}

$\mathrm{p}<0.05$ indicates a significant difference among the two populations

were experienced at least a single attack of malaria during their lifetime respectively.

The protective measures against mosquito bites by two populations were significantly different $(\mathrm{p}<0.05$ at $5 \%$ level of significance). The use of bed net was the predominant practice used against mosquito bites. Among all families, the average number of bed nets per family was 2.04. Some individuals were not used at least on protective measure among the study population in Mannar $(2.04 \%, \mathrm{n}=11)$ and Trincomalee $(3.3 \%, \mathrm{n}=30)$ districts. There was a significant difference of the spraying status of houses among both study communities $(\mathrm{p}<0.05)$.

\section{Socio-economic characteristics}

As suggested by the Paired Chi Square test, two populations were statistically similar in educational level ( $p>0.05$ at $5 \%$ level of significance). Individuals with secondary education (Grade 6-11) were observed as the highest in Mannar $(51.85 \%, \mathrm{n}=1231)$ and Trincomalee $(50.84, \mathrm{n}=1962)$.

The mean monthly income was ranged from 5001 to 10,000 Sri Lankan rupees (Rs) (459.26-918.34 USD). The houses having plastered cement walls with tiled or asbestos roofs were categorized as "Good" (Fig. 3) while un-plastered brick walls with tiled or asbestos roofs were considered as "Moderate" (Fig. 4). All other types were grouped as "Poor" houses (Fig. 5). Of these three categories, the "Moderate" house type was predominant in both Mannar (42.22 \%) and Trincomalee (56.56 \%) districts (Table 3). The occupation types of heads of households among two study populations were varied significantly ( $p<0.05$ at $5 \%$ level of significance).

\section{Bray-Curtis similarity clustering analysis}

The overall clustering status of two populations in terms of demographic, epidemiological and socio-economic characteristics is illustrated in Fig. 6. As suggested by the Bray-Curtis similarity, the two populations in the districts of Mannar and Trincomalee were shared a similarity of $85 \%$ (Fig. 6). The dissimilarity level of $15 \%$ among two populations could be associated with some significant differences in protective measures, spraying status and occupation status of household heads.

\section{Discussion}

The present study was carried out in Mannar and Trincomalee districts of Sri Lanka, which were considered as high-risk areas for malaria infections previously, in order to determine demographic, epidemiological and socio-economic determinants on potential malaria 
Table 2 Malaria epidemiology related characteristics of the study population in Mannar and Trincomalee Districts

\begin{tabular}{|c|c|c|c|c|c|c|}
\hline \multirow[t]{2}{*}{ Characteristics } & \multicolumn{2}{|c|}{ Mannar } & \multicolumn{2}{|c|}{ Trincomalee } & \multirow[t]{2}{*}{$p$} & \multirow[t]{2}{*}{$x^{2}$} \\
\hline & $\mathbf{N}$ & $\%$ & $\mathbf{N}$ & $\%$ & & \\
\hline Knowledge about malaria & & & & & 0.09 & 4.69 \\
\hline Poor & 281 & 52.04 & 579 & 64.33 & & \\
\hline Adequate & 192 & 35.56 & 196 & 21.78 & & \\
\hline Good & 67 & 12.41 & 125 & 13.89 & & \\
\hline Potential breeding sites & & & & & 0.29 & 7.26 \\
\hline Burrow pit & 37 & 6.85 & 79 & 8.78 & & \\
\hline Earth well & 23 & 4.26 & 105 & 11.67 & & \\
\hline Built well & 152 & 28.15 & 171 & 19.00 & & \\
\hline Tank/pond & 80 & 14.81 & 144 & 16.00 & & \\
\hline Paddy field & 48 & 8.89 & 116 & 12.89 & & \\
\hline Cemented tank & 12 & 2.22 & 32 & 3.56 & & \\
\hline None & 188 & 34.81 & 253 & 28.11 & & \\
\hline Use of protective measures & & & & & 0.01 & 16.63 \\
\hline Residual spraying & 36 & 6.67 & 8 & 0.89 & & \\
\hline Bed net & 402 & 74.44 & 534 & 59.33 & & \\
\hline Covering eve and window & 16 & 2.96 & 39 & 4.33 & & \\
\hline Mosquito coil & 16 & 2.96 & 123 & 13.67 & & \\
\hline Integrated approach & 58 & 10.74 & 143 & 15.89 & & \\
\hline Other & 1 & 0.19 & 23 & 2.56 & & \\
\hline None & 11 & 2.04 & 30 & 3.33 & & \\
\hline Past malaria infection & & & & & 0.51 & 0.42 \\
\hline Yes & 7 & 1.30 & 4 & 0.44 & & \\
\hline No & 533 & 98.70 & 896 & 99.56 & & \\
\hline Spraying status of the house & & & & & 0.00 & 85.41 \\
\hline Sprayed & 96 & 17.78 & 54 & 6.00 & & \\
\hline Overdue & 106 & 19.63 & 767 & 85.22 & & \\
\hline Unsprayed & 338 & 62.59 & 88 & 9.78 & & \\
\hline
\end{tabular}

$p<0.05$ indicates a significant difference among the two populations

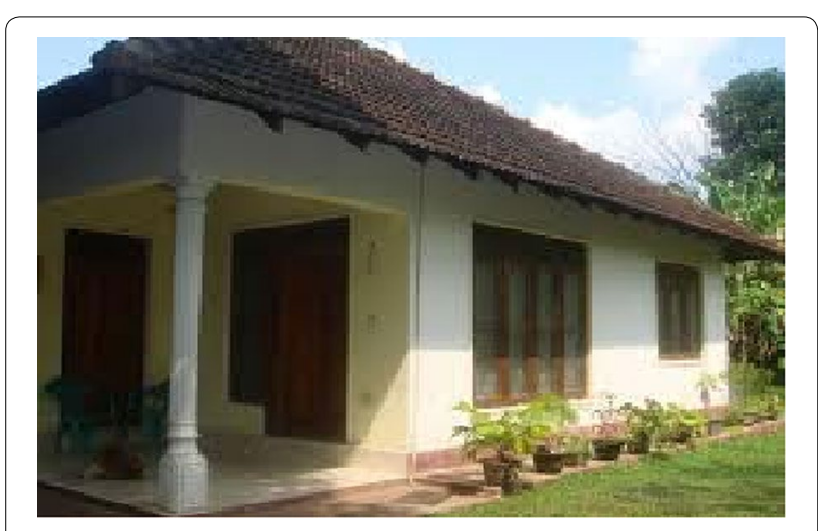

Fig. 3 Example of a "Good" house

transmission and how these factors contributed to low malaria prevalence in the study districts. However, correlations between prevalence of malaria cases and potential risk factors were not able to carry out due to no indigenous cases at present in both districts.

\section{Demographic characteristics}

Demographic and geographical factors such as gender, age, family size and the region where the people live may effect on the risk of malaria transmission [5]. It was observed that the positive malaria diagnostic rate decreases with age and risk of malaria increased per unit increase in family size. Generally, malaria parasite prevalence differed between age and gender with the highest prevalence in children and females. However, only few of them had past malaria infections among the study populations in Mannar (1.3\%) and Trincomalee $(0.44 \%)$. Therefore, no positive correlation was identified in terms of gender, age, family size or region with malaria infection.

From the climatic point of view, the study regions are conducive to malaria epidemics and can be supported 


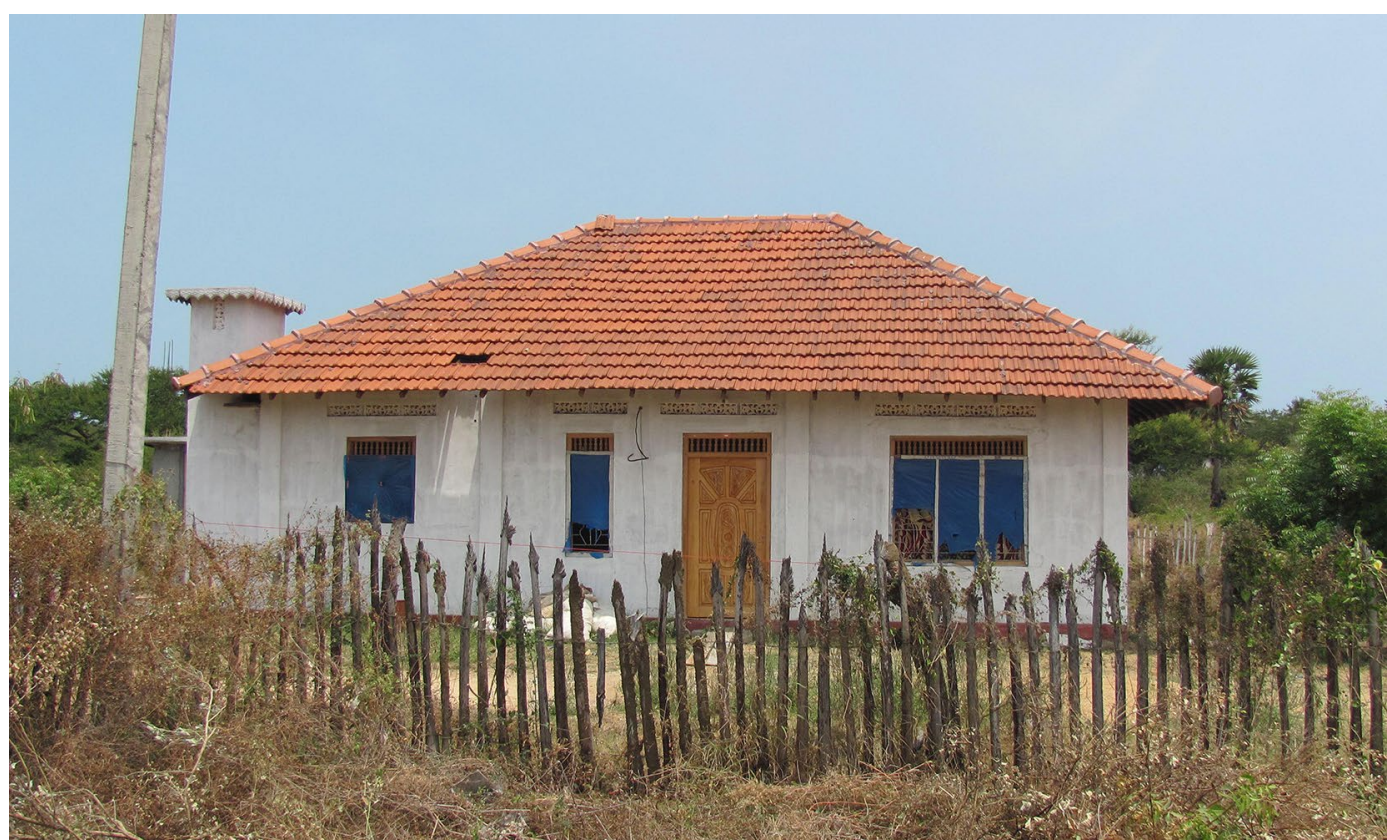

Fig. 4 Example of a "Moderate" house

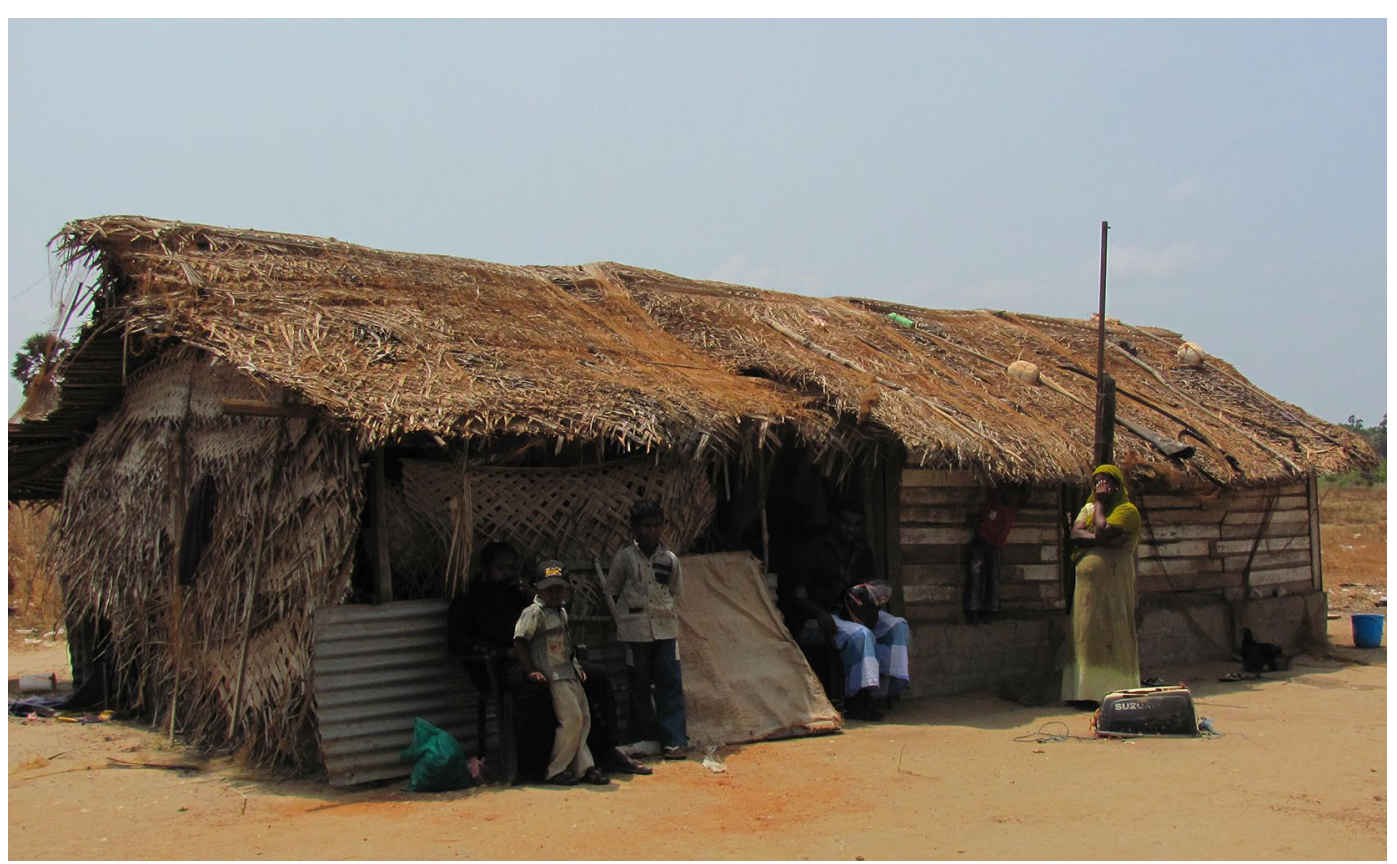

Fig. 5 Example of a "Poor" house

by the presence of malaria vectors, Anopheles culicifacies, Anopheles subpictus, Anopheles annularis, Anopheles varuna and Anopheles tessellatus [6-8]. These areas have been on a steep development trajectory after the end of separatist war in terms of building houses, urban development, road constructions and rapidly growing tourist industry, all of which are associated with increased travel of foreign nationals; and introduction of foreign labour into the country, increasing the number of imported malaria cases [9]. Ongoing construction 
Table 3 Socio-economic characteristics of the study population in Mannar and Trincomalee Districts

\begin{tabular}{|c|c|c|c|c|c|c|}
\hline \multirow[t]{2}{*}{ Characteristics } & \multicolumn{2}{|c|}{ Mannar } & \multicolumn{2}{|c|}{ Trincomalee } & \multirow[t]{2}{*}{$\mathrm{p}$} & \multirow[t]{2}{*}{$x^{2}$} \\
\hline & $\mathbf{N}$ & $\%$ & $\mathbf{N}$ & $\%$ & & \\
\hline \multicolumn{5}{|l|}{ Education level } & 0.59 & 4.63 \\
\hline Bellow school age & 236 & 9.94 & 495 & 12.83 & & \\
\hline $1-5$ & 427 & 17.99 & 810 & 20.99 & & \\
\hline $6-11$ & 1231 & 51.85 & 1962 & 50.84 & & \\
\hline $12-13$ & 321 & 13.52 & 237 & 6.14 & & \\
\hline Diploma & 4 & 0.17 & 3 & 0.08 & & \\
\hline Degree & 24 & 1.01 & 10 & 0.26 & & \\
\hline None & 131 & 5.52 & 342 & 8.86 & & \\
\hline \multicolumn{5}{|c|}{ Monthly income in Sri Lankan Rupee } & 0.43 & 3.79 \\
\hline$\leq 5000$ & 202 & 37.41 & 266 & 29.56 & & \\
\hline $5001-10,000$ & 232 & 42.96 & 372 & 41.33 & & \\
\hline $10,001-20,000$ & 72 & 13.33 & 207 & 23.00 & & \\
\hline $20,001-30,000$ & 18 & 3.33 & 37 & 4.11 & & \\
\hline$>30,000$ & 16 & 2.96 & 18 & 2.00 & & \\
\hline \multicolumn{5}{|l|}{ House type } & 0.12 & 4.11 \\
\hline Good & 112 & 20.74 & 143 & 15.89 & & \\
\hline Poor & 200 & 37.04 & 248 & 27.56 & & \\
\hline Moderate & 228 & 42.22 & 509 & 56.56 & & \\
\hline \multicolumn{5}{|c|}{ Occupation of the head of the household } & 0.003 & 31.11 \\
\hline Army/forces & 1 & 0.19 & 127 & 14.11 & & \\
\hline Carpenter & 6 & 1.11 & 7 & 0.78 & & \\
\hline Driver/conductor & 11 & 2.04 & 12 & 1.33 & & \\
\hline Farmer & 127 & 23.52 & 363 & 40.33 & & \\
\hline Fisherman & 120 & 22.22 & 78 & 8.67 & & \\
\hline Foreign employment & 1 & 0.19 & 11 & 1.22 & & \\
\hline Government servant & 41 & 7.59 & 48 & 5.33 & & \\
\hline Labourer & 132 & 24.44 & 106 & 11.78 & & \\
\hline Mason & 3 & 0.56 & 16 & 1.78 & & \\
\hline Mechanic & 12 & 2.22 & 22 & 2.44 & & \\
\hline Other & 45 & 8.33 & 66 & 7.33 & & \\
\hline Self-employed & 6 & 1.11 & 4 & 0.44 & & \\
\hline Traders/business & 35 & 6.48 & 40 & 4.44 & & \\
\hline
\end{tabular}

$\mathrm{p}<0.05$ indicates a significant difference among the two populations

projects are leading to the creation of new vector breeding sites, including in previously endemic areas. Recent findings identified a conducive breeding of malaria vectors including An. culicifacies sibling species E in waste water containing drains in urban/semi-urban settings [10]. Therefore, changes in the demography have increased the receptivity to malaria in previously endemic areas.

Many of the houses kept animals in their households namely; cattle, goats, dogs, cats and poultry. Since malaria vectors are zoophilic in nature, there is a possibility of attracting vectors to animals. Therefore, the absence of malaria incidence in these study areas may be due to the phenomenon of zooprophylaxis [11]. Some recent studies conducted to determine foraging behaviour of malaria vectors in the country also suggest that human is not the preferred host for tested anophelines [3].

\section{Epidemiological characteristics}

Socio-economic status and human settlement patterns also affect human vulnerability to vector-borne diseases. For example, if preventive measures such as screens, insect repellants or other practices are available and affordable to risk populations of mosquito-borne diseases, infection can be drastically lowered [12]. 


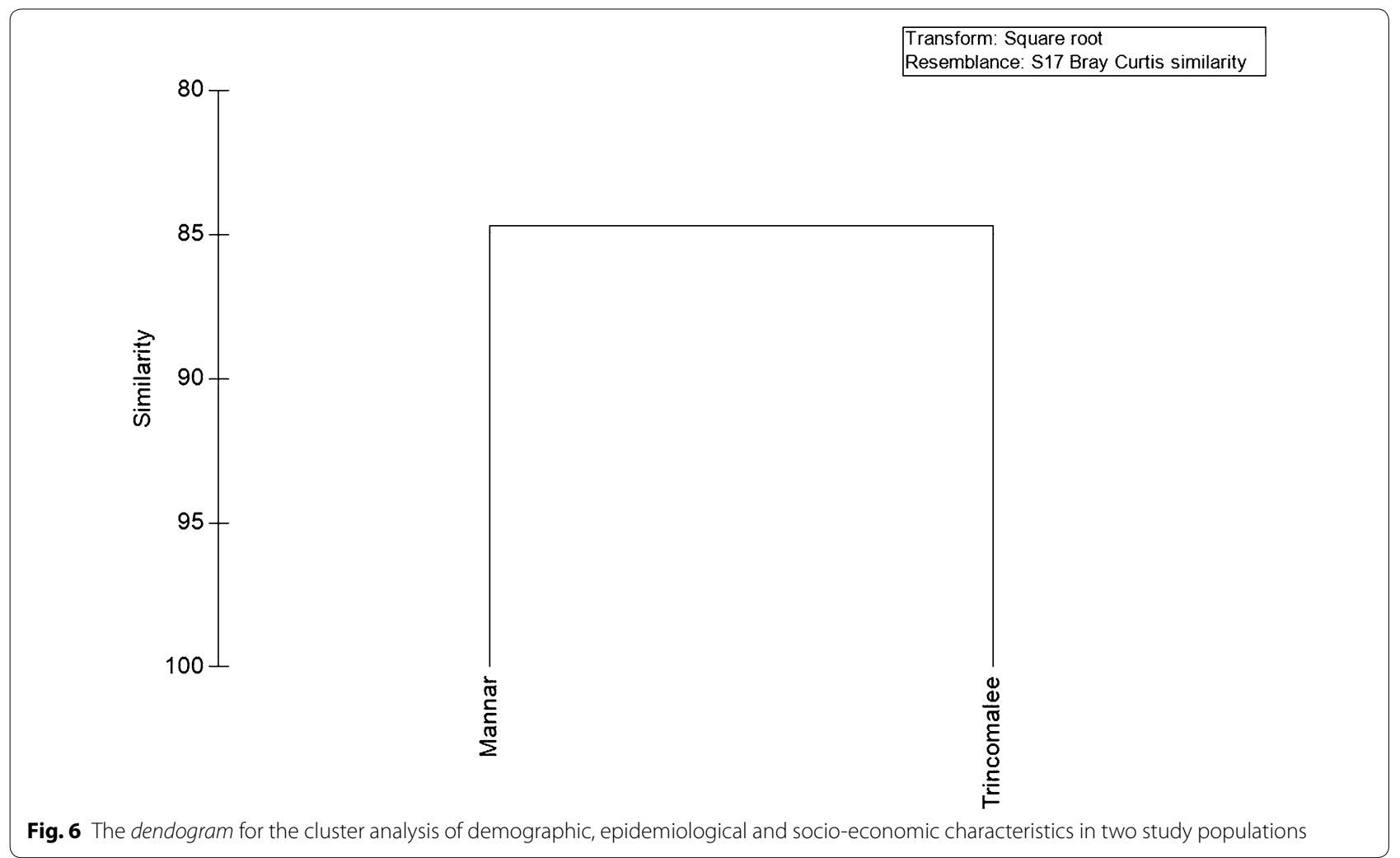

The present case study identified residual spraying, use of bed nets (LLIN, ITN or normal nets), covering eaves/ windows and use of mosquito coils as the main preventive measures against mosquito biting. About 10.74 and $15.89 \%$ in the districts of Mannar and Trincomalee showed integrated vector control methods, which contained at least two preventive measures. In addition, only 0.18 and $2.46 \%$ of the total families surveyed in the districts of Mannar and Trincomalee indicated the use of traditional methods such as creating a smoke with "Maduruthala" (Ocimum sanctum) leaves or coconut shells, applying citronella oil on the skin, which categorized as other preventive measures against mosquito biting. Hence, increasing the use of preventive measures against vector biting has caused a negative impact on the malaria transmission.

The knowledge and awareness has a significant influence on malaria control Individual knowledge, awareness and beliefs may also affect malaria occurrence [13, 14]. However, the awareness of community on malaria was poor. Severity of the disease was also not known by $75 \%$ of the total population surveyed. This may be due to the absence of indigenous cases in the country at present. However, this situation may facilitate to re-emerge the disease as a result of poor awareness about the disease by the community, since the lack of adequate knowledge among the general public about the disease and its prevention is an important contributory factor for the disease transmission [15].

\section{Socio-economic characteristics}

Malaria is considered as a disease associated low income communities with poor socio-economic status because, poor communities have comparatively less access to anti-malarials and anti-mosquito measures, since they cannot afford personal protection measures, a clean environment free of mosquito breeding sites, vulnerable to ineffective diagnosis and treatment due to financial and cultural implications $[5,16]$. Therefore, a better understanding of the relationships between malaria and socioeconomic variables is needed to enable design effective policies and tools to tackle the problem.

The present study revealed that the majorty of these communities were in the middle economic strata lived under "moderate" housing condition. Previous studies conducted in southern Sri Lanka have shown that over $70 \%$ of the malarial episodes were reported from "Poor" houses [12, 17]. It was further explained that the "Poor" house type with mud, cadjan or brick un-plastered walls with thatched or asbestos roofs was the most predominant house type in that study. It is most likely that poorly constructed mud cadjan houses might have a number of 
gaps and holes through which a vector mosquito could easily enter following the scent of human hosts. However, in the present study, "Good" and "Moderate" house types were higher than of "Poor" house type having mud or cadjan wall with cadjan roof, which does not support malaria vector mosquitoes to rest inside houses. Therefore, bricks and cement walls may limit the contact with mosquito vector also reduces the possibility of being bitten by a vector mosquito [5]. Hence, changing living style in these areas may have a negative impact on malaria transmission.

The predominant average monthly income category in both districts was of Rs. 5001-10,000. It is indicative that both districts represented a low economic condition which should be lead to increase "Poor" house type. However, this situation can be explained that due to the availability of resources in these areas have been facilitated them to build or renovate houses to "Moderate" or "Good" conditions and some development activities which were initiated by the government/non-governmental organizations have been significantly influenced on uplifting the house types.

Sri Lanka is an agricultural country in which the majority of the country's population engages in agricultural related activities and lives in traditional malarious areas [17]. The peak of malaria transmission in the county coincided between important agricultural activities during the past. Out of 12 main occupation categories, only $23.54 \%$ from Mannar and $40.33 \%$ from Trincomalee represented "Farmer", which is significantly low when compared to the previous studies conducted in Sri Lanka [17-19]. It seems that majority of the people living in the districts of Mannar and Trincomalee do not engage with direct agricultural activities.

The agricultural activity practices by farmers were paddy cultivation, which dominated by land preparation followed by planting of crops, application of fertilizer, application of agro-chemicals for the control of pest/ weeds and harvesting the crops. In early days, people were used to follow traditional, time consuming practices for land preparation and cultivation till late night. However, as a result of expanding commercial agriculture and use of mechanical equipment have reduced the time consume for agricultural activities. Therefore, number of days stayed outside for ploughing and harvesting or time stays out-door till late evening have been reduced significantly. Hence, the people get less chances of exposing to mosquito bites, which would make them less susceptible to malaria.

Overall, some established risk factors in this study were not associated with malaria transmission. However, current study on potential risk factors affecting transmission of malaria is important for a country which is achieving elimination and entering into prevention of reintroduction phase. Therefore, it is essential to keep the people aware on malaria and especially some people in these districts visit nearby countries like India and Pakistan where still suffering from the disease severely. Hence, these people could be vulnerable to malaria at their visit any time and even from them a reintroduction of malaria could be occurred in the country due to imported cases with the presence of malaria vectors in these areas.

\section{Conclusion}

Improvement in living standard and commercial agriculture were identified as potential factors associated with the reduction of malaria incidence. However, lack of awareness in these communities about the disease may facilitate to re-emerge the malaria incidence. Therefore, these findings would be helpful in better planning and implementation of malaria control strategies in the study areas.

\section{Abbreviations}

Rs: Sri Lankan rupees; LLIN: long-lasting insecticide-treated bed net; ITN: insecticide-treated bed net.

\section{Authors' contributions \\ NG conducting field surveys, data entry, data analysis and writing the manuscript; WA supervision of the surveillance programme and reviewing the manuscript; $\mathrm{MH}$ assisting field survey; RW data analysis and reviewing the manuscript; All authors read and approved the final manuscript.}

\section{Author details}

${ }^{1}$ Department of Parasitology, Faculty of Medicine, University of Kelaniya, Colombo, Sri Lanka. ${ }^{2}$ Molecular Medicine Unit, Faculty of Medicine, University of Kelaniya, Colombo, Sri Lanka. ${ }^{3}$ Department of Public Health, Faculty of Medicine, University of Kelaniya, Colombo, Sri Lanka.

\section{Acknowledgements}

Financial support by the Global Fund for Aids, Tuberculosis and Malaria (GFATM-Round 8- SRL809G11 M.) through TEDHA Malaria Elimination Programme.

\section{Competing interests}

The authors have declared that they have no competing interests.

\section{Availability of data and materials}

This is an analytical cross sectional study conducted among selected individuals in early malaria risk areas of Sri Lanka. Data will not be shared in any of the source in order to maintain the confidentiality of data obtained.

\section{Consent for publication}

Written consent to publish the data on the present study was obtained from each participant.

\section{Ethics approval and consent to participate}

Ethical clearance for the study was obtained from Ethical Review Committee (ERC) of the Faculty of Medicine, University of Kelaniya, Sri Lanka (P92/09/2010). People who were not willing to participate in the study due to one or more of the following reasons: religious beliefs, absence of house head or a feeling that it is not worth participating were not considered for the study. Written consents were obtained from the study participants prior to the interviews and all data collected was kept confidential. 


\section{Funding}

Surveillance activities were funded by the Global Fund for Aids, Tuberculosis and Malaria (GFATM-Round 8-SRL809G11 M.) through TEDHA Malaria Elimination Programme.

Received: 17 April 2016 Accepted: 15 June 2016

Published online: 22 June 2016

\section{References}

1. Gunathilaka N, Abeyewickreme W, Hapugoda M, Wickremasinhe R. Species composition, breeding habitat diversity and habitat characterization of malaria vector breeding habitats in Trincomalee District of Sri Lanka. Biomed Res Int. 2015;2015:823810. doi:10.1155/2015/823810.

2. Gunathilaka PADHN, Fernando MAST, Hapugoda MD, Wijeyerathne $P$, Wickramasinghe AR, Abeyewickreme W. Breeding habitat diversity and species composition of Anopheles mosquitoes in Trincomalee District, Sri Lanka. J Asian Trop Entomol. 2014;3:1-10.

3. Gunathilaka N, Denipitiya T, Hapugoda M, Abeyewickreme W, Wickremasinghe R. Determination of the foraging behaviour and blood meal source of malaria vector mosquitoes in Trincomalee District of Sri Lanka using a multiplex real time polymerase chain reaction assay. Malar J. 2016;15:242.

4. Amarasinghe PH, Amarasinghe FP, Kondadsen F, Fonseka KP, Wirtz RA. Malaria vectors in a traditional dry zone village in Sri Lanka. Am J Trop Med Hyg. 2001;60:421-9.

5. Ayele DG, Zewotir TT, Mwambi HG. Prevalence and risk factors of malaria in Ethiopia. Malar J. 2012;11:195.

6. Gunathilaka N, Fernando T, Hapugoda M, Wickremasinghe R, Abeyewickreme W. Revised morphological identification key to the larval anopheline (Diptera: Culicidae) of Sri Lanka. Asian Pac J Trop Biomed. 2014;3:930-5. doi:10.12980/APJTB.4.2014C941.

7. Gunathilaka N, Fernando T, Hapugoda M, Wickremasinghe R, Wijeyerathne P, Abeyewickreme W. Anopheles culicifacies breeding in polluted water bodies in Trincomalee district of Sri Lanka. Malar J. 2013;2:285.

8. Gunathilaka PADHN. Distribution of major and potential malaria vectors in Mannar and Trincomalee districts and systematics of anophelines in Sri Lanka. Sri Lanka: Ph.D thesis, University of Kelaniya; 2014.

9. Premaratne R, Ortega $L$, Janakan N, Mendis KN. Malaria elimination in Sri Lanka: what it would take to reach the goal. South East Asian J Public Health. 2014;3:85-9.

10. Gunathilaka N, Karunaraj P. Identification of sibling species status of Anopheles culicifacies breeding in polluted water bodies in Trincomlaee District of Sri Lanka. Malar J. 2015:14:214.

11. Gunathilaka PADHN, Fernando MAST, Hapugoda MD, Wijeyerathne P, Wickramasinghe AR, Abeyewickreme W. Resting behavior of malaria vectors in Mannar District of Sri Lanka with reference to zooprophylaxis. In: 14th Annual Research Symposium, University of Kelaniya, Sri Lanka. 2013:130-31.

12. Mendis C, Mendis GAC, de Zoysa AP, Abhayawardena TA, Carter R, Herath PRJ, Mendis KN. Characteristics of malaria transmission in Kataragama, Sri Lanka: a focus for immuno-epidemiological studies. Am J Trop Med Hyg. 1990:42:298-308

13. Yadav K, Dhiman S, Rabha B, Saikia PK, Veer V. Socio-economic determinants for malaria transmission risk in an endemic primary health centre in Assam, India. Infect Dis Poverty. 2014;3:19.

14. Alemu A, Tsegaye W, Golassa L, Abebe G. Urban malaria and associated risk factors in Jimma town, south-west Ethiopia. Malar J. 2011;10:173.

15. Konradsen F, van der Hoek W, Amerasinghe PH, Amerasinghe F. Measuring the economic cost of malaria to households in Sri Lanka. Am J Trop Med Hyg. 1997;56:656-60.

16. Ajayi IO, Jegede AS, Falade CO, Sommerfeld J. Assessing resources for implementing a community directed intervention (CDI) strategy in delivering multiple health interventions in urban poor communities in Southwestern Nigeria: a qualitative study. Infect Dis Poverty. 2013;2:25.

17. Mendis GA. Epidemiological aspects of malaria transmission in Katharagama, Sri Lanka. Sri Lanka: Ph.D thesis, University of Colombo; 1991.

18. Pinikahana J. Irrigation projects, Population movements and malaria transmission. Mosq Borne Dis Bull. 1993;10:48-53.

19. Premasiri DA. Socio-economic, behavioral and environmental aspects of malaria transmission in an endemic area of Sri Lanka. Sri Lanka: Ph.D thesis, University of Colombo; 2006.

\section{Submit your next manuscript to BioMed Central and we will help you at every step:}

- We accept pre-submission inquiries

- Our selector tool helps you to find the most relevant journal

- We provide round the clock customer support

- Convenient online submission

- Thorough peer review

- Inclusion in PubMed and all major indexing services

- Maximum visibility for your research

Submit your manuscript at www.biomedcentral.com/submit
BioMed Central 